\title{
Dog Rabies: An Emerging Infectious Disease at Nyanya-Abuja, Northern Guinea Zone of Nigeria ${ }^{\dagger}$
}

\author{
Osunderu Oluwakemi Abosede * and Akele Esther \\ Forestry Research Institute of Nigeria, Jericho Hills, Ibadan PMB 5054, Oyo State, Nigeria; \\ centralinfo@noun.edu.ng \\ * Correspondence: oaoluwakemi@gmail.com \\ † Presented at the 5th African Conference on Emerging Infectious Diseases, Abuja, Nigeria, 7-9 August 2019.
}

Published: 17 March 2020

\begin{abstract}
The impacts of climate change on livelihood and natural ecosystems have made it imperative to support health leadership in Africa to integrate health into national climate change planning. This paper analyses Rabies as a pressing issue for developing countries like Nigeria to build climate-resilient health systems. Rabies remains a public health problem in Nigeria despite regulations on rabies, dog movement and population control. Most of the reported cases of rabies deaths in man and canines are associated with unvaccinated dogs sharing space with human beings; this can be prevented if appropriate measures are taken. The aim of the study was to assess the risk rabies constitute to the public in the selected study area, Nyanya, Abuja, the Federal Capital Territory. This is a retrospective study on reported cases of dog bite in humans at the General Hospital in Nyanya, Abuja, FCT. Past medical records of patients for a period of 5 years which were randomly selected for the study. Data collected were analysed using descriptive and inferential statistical methods. $100 \%$ of the cases were due to dog exposure. Children between the ages 0-19 years accounted for $98 \%$ of the reported cases while only $2 \%$ occurred in adult. Male children had highest cases of $76 \%$, female children; $22 \%$ and male adult case of $2 \%$. Climate-resilient health systems should include the strengthening of governance and policy, integration of health information systems, preventive and curative service delivery with adaptation options such as morbidity and mortality attributed to rabies and other emerging diseases.
\end{abstract}

Keywords: rabies; Nyanya-Abuja; climate-resilient; children

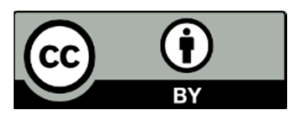

(C) 2020 by the authors. Licensee MDPI, Basel, Switzerland. This article is an open access article distributed under the terms and conditions of the Creative Commons Attribution (CC BY) license (http://creativecommons.org/licenses/by/4.0/). 